\title{
Determinants of Pregnant Mothers to Bypass Primary Health Facilities and Directly Seek Health Care in Hospitals in Dar es Salaam Region-A Cross Sectional Study
}

\section{Joseph C Hokororo ${ }^{1, *}$, Eliudi S Eliakimu ${ }^{1}$, Ruth Ngowi ${ }^{1}$, Mohammed A Mohammed ${ }^{1}$, Hamisi M Malebo ${ }^{2}$, Sehyeon Kim ${ }^{3}$, Nyambuli Jigabha ${ }^{3}$, Jackline Makupa ${ }^{3}$, Fatuma Salimu ${ }^{3}$, Pauline Mtesigwa ${ }^{3}$, Sukyung Kim ${ }^{3}$, Daniel Nkungu ${ }^{4}$ and Akili Mawazo}

${ }^{1}$ Health Quality Assurance Division, Ministry of Health, Community Development, Gender, Elderly and Children, Dar es Salaam, Tanzania

${ }^{2}$ National Commission for UNESCO of the United Republic of Dar es Salaam, Tanzania

${ }^{3}$ Medipeace, Dar es Salaam, Tanzania

${ }^{4}$ Mwananyamala Regional Referral Hospital, Dar es Salaam, Tanzania

${ }^{5}$ Muhimbili University of Health and Allied sciences, Dar es Salaam, Tanzania

*Corresponding author: Joseph C Hokororo, Health Quality Assurance Division, Ministry of Health, Community Development, Gender, Elderly and Children, Dar es Salaam, Tanzania, E-mail: drhokororo@gmail.com

Received: 04 Dec, 2019 | Accepted: 12 Feb, 2020 | Published: 17 Feb, 2020

Citation: Hokororo JC, Eliakimu ES, Ngowi R, Mohammed MA, Malebo HM, et al. (2020) Determinants of Pregnant Mothers to Bypass Primary Health Facilities and Directly Seek Health Care in Hospitals in Dar es Salaam Region-A Cross Sectional Study. J Epidemiol Public Health Rev 5(1): dx.doi.org/10.16966/2471-8211.181

Copyright: (c) 2020 Hokororo JC, et al. This is an open-access article distributed under the terms of the Creative Commons Attribution License, which permits unrestricted use, distribution, and reproduction in any medium, provided the original author and source are credited.

\begin{abstract}
Introduction: Dar es Salaam is the region with a large number of healthcare facilities than any other region in Tanzania. Primary health care facilities (dispensaries and health centers) outnumber the available hospitals. However, hospitals are overwhelmed with patients as compared to primary health care facilities (PHCF) because people tend to skip the primary health care facilities, leading to poor quality of the health care services in secondary facilities due to congestion.
\end{abstract}

Objective: The aim was to identify determinants that influence mothers to bypass primary health care facilities.

Setting: The study was conducted in healthcare facilities in Dar es Salaam region. It targeted all postnatal women who attended hospitals during data collection.

Methodology: A cross-sectional study carried out in December 2018 to assess the determinants associated with pregnant mothers to bypass primary healthcare facilities in their healthcare needs. The sample included all women who attended public hospitals for delivery and consented to the study. A consecutive sampling procedure was used and a total of 544 of respondents were involved. A structured questionnaire was used. Data were analyzed in levels of univariate, bivariate and multivariate using SPSS statistical package number 20.

Results: A total of 544 respondents were interviewed. Out of those respondents, 536(99\%) were above the age of 18 . The majority, were married $(398,73 \%)$, and had daily incomes of more than one USD $(298,92.5 \%)$. The bypass by the respondents of the PHCFs was higher $402(74 \%)$ and only $27(26 \%)$ had referral to the higher facilities hospitals at Council [Level one Hospital] and Regional Level [Level 2 Hospital] than primary facilities.

Conclusion: This study has found that seven of every ten pregnant women surveyed had bypassed the primary health care facilities. Findings from this study reveal a strong and urgent need to 1 . Strengthen primary healthcare facilities to make them more attractive to people and 2 . To better implement the referral guidelines to reduce this bypass.

Keywords: Determinants; Skipping of primary health facilities

List of Abbreviations: AIDS-Acquired Immune Deficiency Syndrome; ANC-Antenatal Care; AOR-Adjusted Odds Ratio; ARV-Antiretroviral; BMIBody Mass Index; BSHFs-Basic Standards for Healthcare Facilities; HAls-Healthcare Associated Infections; Hb level-Haemoglobin level; HFR-Health Facility Registry; HIV-Human Immunodeficiency Virus; IRB-Institutional Review Board; LHRC-Legal and Human Rights Centre; MDGs-Millennium Development Goals; MNH-Muhimbili National Hospital; MoHCDGEC-Ministry of Health, Community Development, Gender, Elderly and Children

\section{Introduction}

Maternal mortality is one of the global concerns as it is unacceptably high. World Health Organization (WHO) estimates about 830 women pass away from pregnancy or childbirth related complications around the world every day. Almost all maternal deaths (99\%) occur in developing countries and more than half of these deaths occur in sub-
Saharan Africa. The Maternal Mortality Ratio (MMR) in developing countries was 239 per 100,000 live births versus 12 per 100,000 live births in developed countries in 2015 . There are large disparities that exist between countries, and within countries; between women with high and low income and those women living in rural versus urban areas [1]. Tanzania is among the countries in Sub Saharan Africa with 
high MMR and high neonatal mortality rate (NMR). According to Tanzania One Plan II of 2015, the country is facing a MMR of 410 per 100,000 live births. This number is incredibly high in a country with health facilities around 8,000 . The high mortality ratio might be due to the bypass of lower facilities to go to higher facilities leading to compromised quality of services at high levels. These facts have led MMR to be among the international agenda and adopted by the United Nations General Assembly in the Millennium Development Goals (MDGs) and now in the Sustainable Development Goals (SDGs) with the target to mitigate the situation [2]. One of the means to mitigate the MMR is to attain universal access to reproductive health by ensuring antenatal care coverage is worldwide $[3,4]$. Tanzania aligned with the WHO's ambition of ensuring universal access of health care services to all. The country decided to establish Primary Health Service Development Programme (2007-2017), which aimed at promoting access to basic health care. Planned under the programme was construction of dispensary in every village and health centre in each ward [5]. The number of health facilities has been increasing substantially-in fiscal year (FY)-2012/2013, there were a total of 5,052 health facilities; in FY-2013/2014, there were 6,270 health facilities [6] and in FY-2018/2019 there were about 8,000 facilities [7]. The facilities are widely spread in the country on one side and the percentage of population that is living within 5 kilometers has been increasing progressively from 2009 (48\%), in 2010 (50.6\%) and in $2012(71.9 \%)$ on the other side [6]. Dar es Salaam region has larger number of facilities than other regions. The expectation of Tanzanian Government was to see patients and clients receiving health services from those Primary Health Care Facilities (PHCFs)-dispensaries and health centers, while the specialized and complicated cases are referred to the hospitals (Level 1-Council Hospital, Level 1-Regional Referral Hospital, Level 3-Zonal Referral Hospital, and then National Hospital) for advanced and specialized care. Further to that, Kante AM, et al. [8] explained that in the Tanzanian health system, women are expected to first visit their nearest primary health facility for normal delivery and other uncomplicated health care services which is not happening. As a result of bypassing PHCFs, hospitals are overcrowded which compromises, the quality of services and care provided by the hospitals that are already stretched with other problems like shortage of human resources, poor infrastructure, shortage of human resources. Hence, overcrowding in those hospitals lead to poor services to patients such as sharing of beds, shortage of medicines, lack of timely services, and increased health care associated infections (HAIs).

The extent of bypassing lower facilities is alarming. In Kenya, Audo $\mathrm{MO}$, et al. [9] found that at least half of the women bypass their closest facility (often the lowest level government facilities) for antenatal care (ANC), immunisation and treatment of their children; and Escamilla $\mathrm{V}$, et al. [10] found that $88.0 \%$ of women bypassed for delivery services, $83.9 \%$ bypassed for facility-based contraceptive use, and $84.2 \%$ bypassed for child health visits. Also, Cohen J, et al. [11] noted that some patients in peri-urban areas of Nairobi bypassed public owned facilities despite of being free and went to private facilities seeking for high quality care. Likewise, in Ghana Yafee AQ, et al. [12] established that, $33.9 \%$ was the total rate of bypassing a local facility and in Sudan, Ahmed ME, et al. [13] found that primary health facility bypass was very high at $87 \%$ to secondary hospitals. In India, it has been reported that decision by women to bypass nearby health facility is contributed to inadequate capacity of primary health care facilities in impoverished states to provide basic delivery and newborn services, and preference of women for quality care [14]; and in two other studies in Gujarat and Madhya Pradesh, the bypass was reported to be 37.7\% [15] and 38\% [16] respectively. Yao J, et al. [17] have reported on bypass in Mozambique, in which they found that perception on service quality and individual characteristics such as economic condition of household, age, and HIV status contribute to decision to bypass nearest facility [17]. Also, in Nepal $55 \%$ of women bypassed the nearest birthing facility to go to a hospital [18]. In Sierra Leone, about $87 \%$ of women in an urban area would bypass their nearest inpatient care facility to a government hospital where there is low-cost and comprehensive care [19]. Also, Perera SK, et al. [20] have reported reasons for bypass in Sri Lanka to include availability of better facilities and expectation of good quality of services [20]. In a rural district in Uganda, 425 (72.16\%) out of 589 women who bypassed, went to a district hospital [21].

Tanzania experiences the same as what has been found elsewhere in the world. There is overcrowding in the secondary and tertiary hospitals. The overcrowding is too much in some of the facilities such that mothers, who give birth, sleep on the floor. The situation was proved by the Legal and Human Rights Commission (LHRC) report of 2015 [22] and Kante AM, et al. 2016 [8] that, 75.4\% bypassed the primary facilities in rural Tanzania. In a rural district in western Tanzania, $44 \%$ of women who delivered in a health facility bypassed their nearest facility [23] and in Pwani region, $41.8 \%$ of women who delivered in health facility were bypassers [24].

People who bypass the PHCFs and go to the hospitals have several reasons to do so. Visser CA, et al. [25] at Letaba Hospital in South Africa confirmed that the three most common reasons indicated by participants for bypassing their local clinics were: (1) to see a doctor (31.1\%); (2) to see a dentist $(24.2 \%)$; and (3) for a termination of pregnancy (10.9\%). He also established that, other people bypassed the PHCFs were between the ages of 20 and 40 years, 173 (59.05\%) (Mean age: 29.39 years; $95 \%$ CI: 27.63-31.15,); secondary or tertiary education and more $186(63.48 \%)$ [25]. In Kenya, the reason for bypass were perceived quality of care in the facilities [9] and mothers looking for high quality care [11]. In India, bypass is contributed by functional capacity of facilities and women preference for quality care $[14,15]$. In Nepal, the reason for bypass included "lack of operation, video $\mathrm{X}$-ray and blood test facilities" [18]. In Sri Lanka-availability of better facilities in a hospital, dissatisfaction with quality of care during a previous visit to a different facility, and expectation of good quality at a hospital were the reasons for bypassing primary health facilities [20]. Other reasons of mothers and others to bypass the primary facilities to go to the higher facilities in some rural districts in Tanzania were having complications of previous pregnancy; hence the mothers tend to prefer to seek the higher levels of the health care straightway [8]. It has also been reported that mothers who reported a complication during their current pregnancy were more likely to bypass their nearest facility for childbirth than those who did not adjusted odds ratio $[A O R] 1.88,95 \%$ confidence interval [CI]: 1.22-2.90) [8] Ahmed $\mathrm{ME}$, et al. [13] in Sudan identified the reasons for bypassing the closest public health facilities include unavailability of doctors, lack of health insurance services and higher cost of services [13].

The extent of bypass as well as determinants for bypass is not clear in Dar es Salaam. Although policy guidelines on health system and referral system are available, there is a gap in terms of adherence to that system. Despite having a large number of PHCFs, it appears that the hospitals are more overwhelmed with patients compared to the lower facilities. A study by Simba DO, et al. [26] found that up to $72.5 \%$ of patients admitted at Muhimbili National Hospital (MNH) were self referrals with "more that 70 requiring admission but not necessarily at tertiary level" hospital, hence, limiting the role of providing specialized services and compromised the provision of quality services [26]. Overcrowding of patients in the hospital has been shown to be 
a potential cause of HAIs spread [27]. HAIs have bad consequences not only to the hospitals but also to the patients, health care workers, owners of the facilities (private and public) as well as resulting to an increase in antimicrobial resistance [28]. Furthermore, HAIs causes prolonged stays of patients in the hospitals, increases the use of hospital resources and increase risk of mortality [29,30]. Therefore, there existed a need to carry out an assessment to define the extent of bypass as well as factors for bypass PHCFs in Dar es Salaam region.

The aim of this study was to assess the prevalence and identify associated determinants of pregnant mothers' bypass of PHCFs (dispensaries and health centers) and prefer going directly to the hospitals. Specifically, to assess the prevalence of mother who give birth at public hospitals at council or regional level in five Municipal Councils of Dar es Salaam region without referral; to identify the determinants of pregnant mother's bypass of primary health facilities; and to establish the associated determinants of pregnant mothers' bypass as shown in conceptual framework (Figure 1).

\section{Methods}

A cross-sectional study was conducted in November 2018, on assessment of the associated determinants of pregnant mothers to bypass primary health care facilities and prefer going directly to hospitals in Dar es Salaam region. Five Municipal Councils in Dar es Salaam, Tanzania; Ilala, Kigamboni, Kinondoni, Temeke and Ubungo were involved. The estimated population of Dar es Salaam is 4,364,541 according to census of 2012. Every Municipality had a hospital that serves as a district hospital and have regional referral hospitals (RRHs); Ilala-Amana RRH, Kinondoni-Mwananyamala RRH, Temeke-Temeke $\mathrm{RRH}$ at level two while Kigamboni and Ubungo have level one hospitals. According to the health system of Tanzania, these Hospitals are supposed to handle only referral cases from PHCFs.

The target population was pregnant women in catchment population of the district and regional referral hospitals. Study population involved all pregnant women who attended Dar es Salaam regional and district hospitals during the study period and consented to participate in the study. Participants with critical condition or unable to communicate were excluded. A consecutive sampling procedure was used for all postnatal women who met selection criteria.

Sample was estimated by the following formula: ' $n$ ' $=\left[z 1-\alpha^{2 \star} p(1-\right.$ p)] $/ \mathrm{d}^{2}$; assuming $\mathrm{Z} 1-\alpha^{2}$ is the standard normal value, which at the $95 \% \mathrm{CI}$ it is 1.96 and $\mathrm{Z} \beta$ is the standard normal value corresponding to 1 -power is -0.84 at the $95 \%$ CI level. ' $N$ ' is the sample size, ' $p$ ' is expected proportion of reported pregnant mothers who bypassed the primary facility levels and preferred to go to hospitals for giving birth in the population based on previous study, $\mathrm{d}$ is the absolute error or precision of 5\%. Using 41.8\% found in Pwani region of Tanzania by Kruk ME, et al. [24] and substituting the values in the formula: $\mathrm{n}=\left[1.96^{2 *} 0.42(1-0.42)\right] / 0.05^{2}$, estimated minimum sample size was 375 . However, in this study the sample we used was 544 . The sampled cases were based on the ratio of the population in the councils. Kinondoni is 929,681 , Ilala is $1,220,611$, Temeke is $1,205,949$, Ubungo is 845,368 and Kigamboni is 162,932 (2012 census). The research
Factors related to Primary Health Care Services:

a) Limited antenatal care

b) Lack of health care workers,

c) Lack of privacy,

d) Use of abusive language,

e) Corruption,

f) No

g) medicines No

h) diagnostic

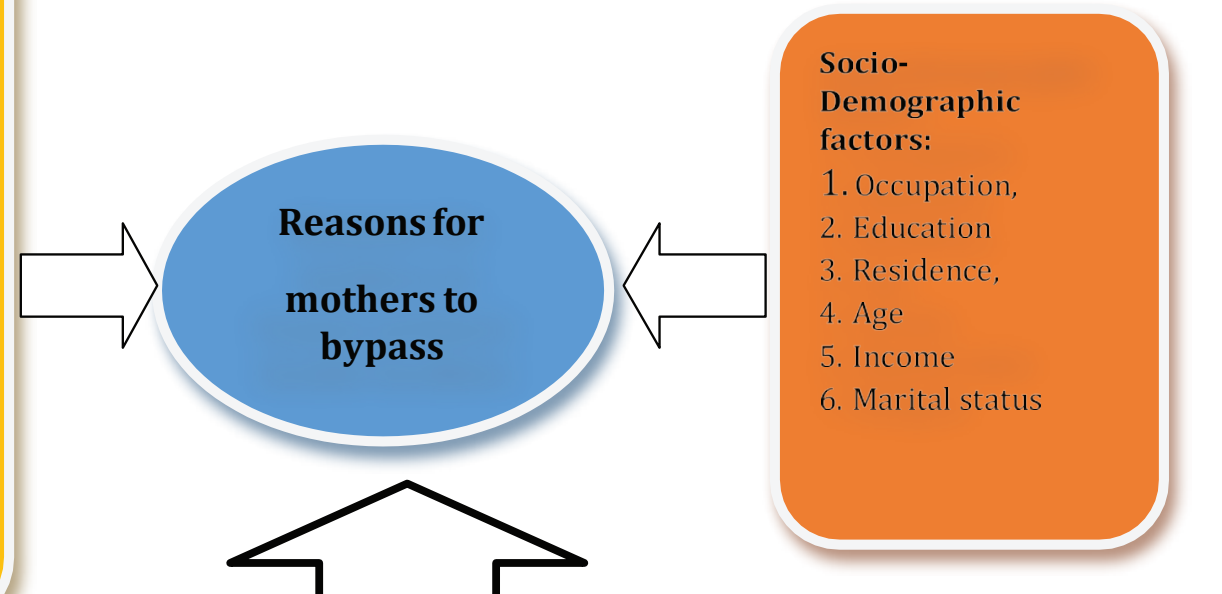

Clinical factors:

1. Any infection, e.g., Malaria, syphilis, etc.

2. Any NCD, e.g., Hypertension, Diabetes Mellıtus, etc.

3. Other Risks, e.g., Previous adverse birth outcome history, Rh factor, CD 4, HIV stage, Parity, Spacing, BMI, History of multiple pregnancy (ies), On ARV, HB level during pregnancy.

Figure 1: Conceptual Framework 
questionnaire contained questions grouped in three domains: (i) social demographic factors; (ii) health services factors; and (iii) clinical factors. The social demographic factors of the mother included: age, marital status, residence, education level, income level, religion, and occupation. Health services provision factors assessed at the primary facilities were: Antenatal Care (ANC) attendance and care; no enough health care workers; no privacy and use of abusive language. Clinical factors of the mothers: any history of infection during pregnancy; $\mathrm{Rh}$ factor of the mother; parity; spacing between pregnancy; Body Mass Index (BMI); Non Communicable diseases (NCDs) like Hypertension; Diabetes Mellitus; previous adverse birth outcome history; history of multiple pregnancy(ies); on ARV; and Blood Hemoglobin (Hb) level during pregnancy. These independent variables were compared to dependent variable: mothers who bypassed the PHCFs level of care to go to hospitals in Dar es Salaam for delivery.

Structured questionnaires were developed in English later translated into Kiswahili language. The questionnaires were pre-tested and used to collect quantitative information. Ten research assistants were trained on the fundamentals of research data management and the tool. The researchers interviewed the consented women at postnatal ward in the hospitals; checked for completeness of the data; cleaned, edited, coded and double entered the data in EPIDATA and then exported to SPSS for analysis. Filled questionnaires were stored in a safe place. Confidentiality of the collected data was assured and presented without participant identifier.

Three levels of analysis were employed. Level one: univariate analysis, in which histograms or pie charts were used to display the data. Frequencies and percentages were used to calculate variables as well as ratio of pregnant women who bypassed the PHCFs. Level two: bivariate analysis was used to determine (associated determinants) various independent determinants as the potential confounder for pregnant mothers to bypass PHCFs (dispensaries and health centres) and prefer going directly to hospitals in Dar es Salaam region and the outcome variable (PHCFs bypass). Continuous variables were categorized and some of the variables were analyzed using Chi square test or Fischer's exact test. A significance level of $\mathrm{P}<0.05$ was considered significant. Odds ratios (OR) were used to measure association at confidence intervals $(95 \% \mathrm{CI})$. Level three: multivariate analysis was used to assess for confounding of the independent variables among all factors. A factor with a difference of at least $10 \%$ between the adjusted odds ratios (AOR) and the crude OR was considered confounding. Factors with p-value 0.2 or less at bivariate analysis were selected for further multivariate analysis. Logistic regression model for analysis was used to explain association amongst factors of pregnant mothers' bypass of PHCFs and prefer going directly to hospitals in Dar es Salaam region.

\section{Results}

\section{Level one analysis}

Demographic characteristic of the study respondents: A total of 544 respondents were interviewed but the number differs in some of the variables as the respondents were free to drop some of the question if they did not feel comfortable to respond to them. Out of those respondents, 536(99\%) were above the age of 18. Of those respondents, 398(73\%) were married and $146(27 \%)$ were single. The study demonstrated that, $282(60.3 \%)$ respondents had secondary education and above, $331(60.85 \%)$ of the spouse were unemployed and those with daily income of above one USD were 298(92.5\%) among the respondents. The bypass by the respondents of the PHCFs was high $402(74 \%)$ and only $27(26 \%)$ had referral to the higher facilities (hospitals).
Health services factors: The antenatal attendance and frequency were assessed among respondents. This study found that, out of 428 respondents, 422(98.6\%) had visited ANC, only 149(34.8\%) had attended four times or more during the pregnancy period. See table 1a and $1 \mathrm{~b}$ for more details.

Clinical factors of respondents: The mode of delivery and history of infection during pregnancy period are shown in figures 2 and 3 respectively. The study showed that, the history of infection during pregnancy occurred in $218(40 \%)$ of respondents. The utilization of the family planning was also assessed. Out of 539 respondents, 226(41.9\%) had the first child and 313(58.1\%) were not coming for the first child. Time between the pregnancy for most of the respondents was two years and above as reveled by $305(75.5 \%)$ of the respondents. It was also found that, out of 544 respondents, 27(5\%) had multiple pregnancy. Other factors affecting respondents' health to bypass the PHCFs are showed in table $2 \mathrm{a}$ and $2 \mathrm{~b}$.

\section{Level two analysis}

Bivariate analysis was done to establish association between independent variables as potential confounders with respect to the outcome variable (bypass of the PHCFs). Bivariate analysis was between sociodemographic factors, health services factors and clinical factors versus bypass of primary level of healthcare.

At bivariate analysis for sociodemographic: It was found that, for those aged 18 and above were more likely to skip the primary facilities $(\mathrm{OR}=2.9, \mathrm{CI}=0.3-24.7, \mathrm{P}$ Value=0.3 $)$ than below age of 18 . Women living in urban areas were more likely to skip the primary facilities $(\mathrm{OR}=1.47, \mathrm{CI}=0.3-5.9, \mathrm{P}$ value 0.4$)$ than those living in rural areas. A mother married to a man with education of secondary and above were more likely to skip the primary facilities $(\mathrm{OR}=1.47, \mathrm{CI}=0.65-3.31$, $P$ value 0.3$)$ than below secondary education. Mothers with education of secondary and above were more likely to skip the primary facilities $(\mathrm{OR}=1.49, \mathrm{CI}=0.6-3.3, \mathrm{P}=0.2)$ than mothers with below secondary education. Details as shown in table $2 \mathrm{C}$. Factors that had $\mathrm{p}$-value $=0.2$, were added into third level of analysis discussed in health services factors.

Table 1a: Health facilities factors and respondent views.

\begin{tabular}{|l|c|c|c|}
\hline \multicolumn{1}{|c|}{ Variable description } & Respondent & Number & Percentage \% \\
\hline $\begin{array}{l}\text { Enough provider patient } \\
\text { discussion time at secondary } \\
\text { and tertiary health facilities }\end{array}$ & Yes & 424 & $91.60 \%$ \\
\cline { 2 - 4 } & No & 39 & $8.40 \%$ \\
\hline $\begin{array}{l}\text { No access to health } \\
\text { information in primary } \\
\text { facilities }\end{array}$ & No & 405 & $87.40 \%$ \\
\hline \cline { 2 - 4 } $\begin{array}{l}\text { Availability of medication at } \\
\text { primary facilities }\end{array}$ & Yes & 417 & $12.60 \%$ \\
\cline { 2 - 4 } $\begin{array}{l}\text { Easy to access secondary and } \\
\text { tertiary HFs }\end{array}$ & Yes & 41 & $84.00 \%$ \\
\cline { 2 - 4 } & No & 41 & $91.00 \%$ \\
\hline
\end{tabular}

Table 1b: Health facilities factors and respondent views.

\begin{tabular}{|l|c|c|c|}
\hline \multicolumn{1}{|c|}{ Variable description } & $\begin{array}{c}\text { Respondent } \\
\text { views }\end{array}$ & $\begin{array}{c}\text { Number } \\
\text { (N) }\end{array}$ & Percentage \% \\
\hline $\begin{array}{l}\text { No quality health care services } \\
\text { at primary facilities }\end{array}$ & Yes & 383 & $85.00 \%$ \\
\cline { 2 - 4 } & No & 69 & $14.00 \%$ \\
\hline \multirow{2}{*}{ No Privacy at PHF } & Yes & 434 & $95.00 \%$ \\
\cline { 2 - 4 } $\begin{array}{l}\text { No sufficient equipment at } \\
\text { PHF }\end{array}$ & No & 22 & $5.00 \%$ \\
\cline { 2 - 4 } & No & 422 & $92.00 \%$ \\
\hline
\end{tabular}




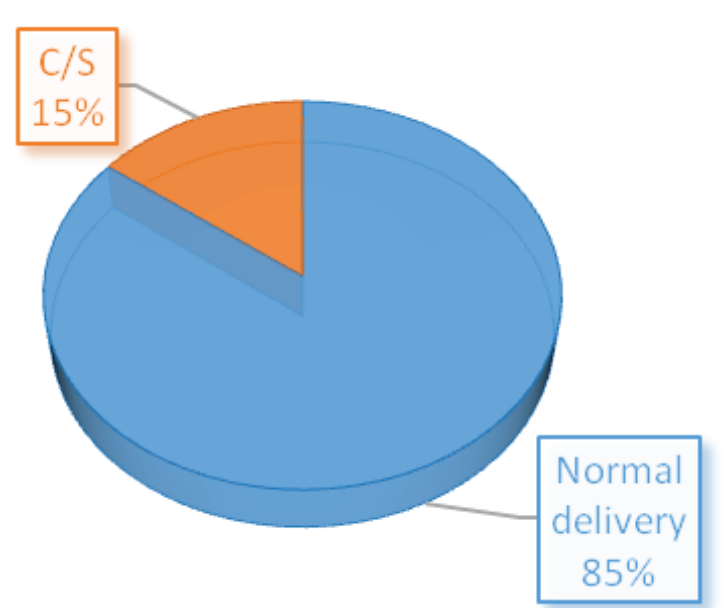

Figure 2: Showing mode of delivery.

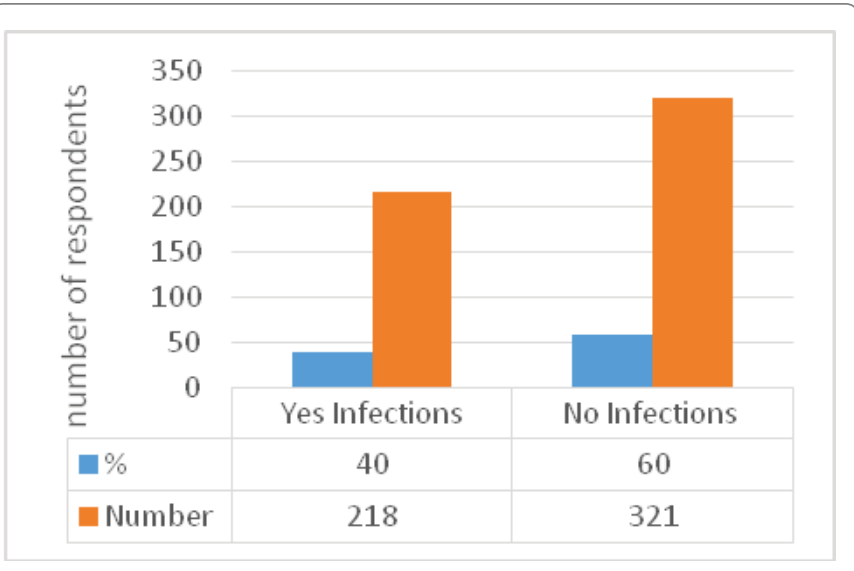

Figure 3: Showing history of infection during pregnancy.

Bivariate analysis between factors related to primary health care services and bypass of primary facilities $(\mathrm{N}=\mathbf{5 4 4})$ : At bivariate analysis for factors related to Primary Health Care Services, it was found that women who admitted nurses at primary facilities treat patients well were more likely to skip the primary facilities $(\mathrm{OR}=1.5$, $\mathrm{CI}=0.5-4.1, \mathrm{P}=0.2)$ than those who did not admit. Those who said primary facilities were clean were more likely to skip the primary facilities $(\mathrm{OR}=1.2, \mathrm{CI}=0.3-4.0, \mathrm{P}=0.5)$ than those who said they were dirty. Women who acknowledged that, medicines were available at PHCFs were more likely to skip the primary facilities $(\mathrm{OR}=1.3, \mathrm{CI}=0.3$ $4.5, \mathrm{P}=0.4$ ) than those who said the medicines were not available.

Women who admitted that there is a low-quality health care service at primary facilities were more likely to skip the primary facilities $(\mathrm{OR}=0.7, \mathrm{CI}=0.1-2.3, \mathrm{P}=0.3)$ than those who said the quality is good. Those who admitted that, at primary facilities had no privacy, were likely to bypass the primary facilities than those who did not admit it $(\mathrm{OR}=3.9, \mathrm{CI}=1.2-12.7, \mathrm{P}$ value $=0.03)$. Those who said there was corruption at primary facilities were likely to bypass the primary facilities $(\mathrm{OR}=3.9, \mathrm{CI}=1.2-12.7, \mathrm{P}=0.03)$ than those who said there were no corruption. Those who said there are no equipment at primary health facility were more likely to skip the primary facilities $(\mathrm{OR}=1.5$, $\mathrm{CI}=0.4-5.3, \mathrm{P}$ value $=0.3)$ than those who said they were available. The
Table 2a: Proportional of Clinical factors among respondents.

\begin{tabular}{|l|c|c|}
\hline \multicolumn{1}{|c|}{ Variable description } & Response & Number (\%) \\
\hline \multirow{2}{*}{ Name of infections ( $\mathrm{n}=219)$} & UTI or Malaria & $164(74.9 \%)$ \\
\cline { 2 - 3 } & Others & $55(25.10 \%)$ \\
\hline \multirow{2}{*}{ NCDs (Hypertension and DM) ( $=544)$} & Yes & $29(5.30 \%)$ \\
\cline { 2 - 3 } & No & $515(94.70 \%)$ \\
\hline \multirow{2}{*}{ Previous birth complications ( $=539)$} & Yes & $44(8.00 \%)$ \\
\cline { 2 - 3 } & No & $495(92.00 \%)$ \\
\hline \multirow{2}{*}{ STDs ( $n=539)$} & Yes & $12(2.20 \%)$ \\
\hline \multirow{2}{*}{} & No & $527(97.80 \%)$ \\
\cline { 2 - 3 } & Yes & $318(58.50 \%)$ \\
\cline { 2 - 3 } & No & $226(41.50 \%)$ \\
\hline
\end{tabular}

Table 2b: Clinical factors.

\begin{tabular}{|l|c|c|}
\hline \multicolumn{1}{|c|}{ Variable description } & Response & Number (\%) \\
\hline \multirow{2}{*}{$\begin{array}{l}\text { History of admission during } \\
\text { pregnancy }\end{array}$} & Yes & $81(15 \%)$ \\
\cline { 2 - 3 } Weight loss during pregnancy & No & $459(85 \%)$ \\
\cline { 2 - 3 } & Yes & $82(15.3 \%)$ \\
\hline \multirow{2}{*}{ Number of pregnancies in the past } & No & $459(84.7 \%)$ \\
\cline { 2 - 3 } & $\begin{array}{c}\text { 2-times and } \\
\text { above }\end{array}$ & $316(58.1 \%)$ \\
\hline \multirow{2}{*}{ Time between pregnancy } & 2-years and less & $99(24.5 \%)$ \\
\cline { 2 - 3 } & 2-years and above & $305(75.5 \%)$ \\
\hline
\end{tabular}

detail is shown in table $2 \mathrm{~d}$. Factors that had $\mathrm{p}$-value $=0.2$, were added into third level of analysis discussed in health services factors.

Bivariate analysis between clinical factors and bypass of primary facilities ( $\mathbf{N = 5 4 4 ) : ~ W o m e n ~ a t t e n d e d ~ a n t e n a t a l ~ c l i n i c ~} 4$ times and above were more likely to skip the primary facilities $(\mathrm{OR}=0.94$, $\mathrm{CI}=0.9-0.96, \mathrm{P}$ Value $=0.07$ ) than those who attended below 4 times. Those who got infection during pregnancy were more likely to skip the primary facilities $(\mathrm{OR}=1.5, \mathrm{CI}=0.6-3.3, \mathrm{P}$ value $=0.2)$ than those who had no infection. Those who had Non-Communicable Disease during pregnancy, were more likely to skip the primary facilities $(\mathrm{OR}=1.6$, $(\mathrm{CI}=0.2-11.8, \mathrm{P}$ value=0.5) than those who did not. Those who had birth complication in the previous pregnancies were more likely to skip the primary facilities $(\mathrm{OR}=1.2, \mathrm{CI}=0.2-5.1, \mathrm{P}=0.5)$ than who had no complication. Women who had first pregnancy were more likely to skip the primary facilities $(\mathrm{OR}=1.12, \mathrm{CI}=0.5-2.4, \mathrm{P}$ value $=0.4)$ than those who had second and above. Those who had been admitted during pregnancy were more likely to skip the primary facilities $(\mathrm{OR}=0.45$, $\mathrm{CI}=0.1-1.1, \mathrm{P}=0.06)$ than those who had not admitted. Those who had shorter space between pregnancies, less than two years were more likely to skip the primary facilities $(\mathrm{OR}=0.6, \mathrm{CI}=0.2-1.5, \mathrm{P}=0.2)$ than those with long spacing. The detail is shown in table $2 \mathrm{e}$ and 3 . Factors that had $p$-value $=0.2$, were added into third level of analysis discussed in Health services factors.

\section{Multivariate analysis}

Variables considered for multivariate analysis were those with a p-value of 0.2 and below. They included marital status, education of the mother, occupation of the spouse, daily income, courtesy treatment of the nurses, courtesy treatment of clinicians, enough time to discuss with health providers, history of infection during pregnancy, type of infection, history of STDs, Hb level during pregnancy, history of 
Table 2c: Association between demographic factors and bypass of the PHFs.

\begin{tabular}{|c|c|c|c|c|c|}
\hline \multirow[t]{2}{*}{ Variable } & \multicolumn{5}{|c|}{ Reasons for mothers to bypass primary health facilities } \\
\hline & No, n (\%) & Yes n (\%) & OR & $\mathrm{CL}$ & $\mathrm{P}$ \\
\hline \multicolumn{6}{|l|}{ Value } \\
\hline \multicolumn{6}{|c|}{ Courtesy Treatment by Nurses at primary facilities } \\
\hline Yes & $385(94.4 \%)$ & $23(5.6 \%)$ & 1 & & \\
\hline No & $56(91.8 \%)$ & $5(8.2 \%)$ & 1.5 & $0.5-$ & 0.2 \\
\hline \multicolumn{6}{|c|}{ Courtesy Treatment by Clinicians at primary facilities } \\
\hline Yes & $381(94.4 \%)$ & $23(5.6 \%)$ & & & \\
\hline No & $51(92.7 \%)$ & $4(7.3 \%)$ & 1.3 & $0.4-$ & 0.4 \\
\hline \multicolumn{6}{|c|}{ PHF cleanliness } \\
\hline Yes & $386(94.1 \%)$ & $24(5.9 \%)$ & & & \\
\hline No & $42(93.3 \%)$ & $3(6.7 \%)$ & 1.2 & $0.3-$ & 0.5 \\
\hline \multicolumn{6}{|c|}{$\begin{array}{l}\text { Enough provider patient discussion time at secondary and tertiary } \\
\text { health facilities }\end{array}$} \\
\hline Yes & $383(94.6 \%)$ & $22(5.4 \%)$ & & & \\
\hline No & $52(91.2 \%)$ & $5(8.8 \%)$ & 1.7 & $0.6-4.6$ & 0.2 \\
\hline \multicolumn{6}{|c|}{ No access to health information in primary facilities } \\
\hline Yes & $400(94.3 \%)$ & $24(5.7 \%)$ & & & \\
\hline No & $36(92.3 \%)$ & $3(7.7 \%)$ & 1.4 & $0.3-4.9$ & 0.4 \\
\hline \multicolumn{6}{|c|}{ Availability of Medication at primary facilities } \\
\hline Yes & $362(93.8 \%)$ & $24(6.2 \%)$ & & & \\
\hline No & 71(95.9\%) & $3(4.1 \%)$ & 0.6 & $0.6-4.1$ & 0.3 \\
\hline \multicolumn{6}{|c|}{ Easy to Access secondary and tertiary HF } \\
\hline Yes & $393(94.2 \%)$ & $24(5.8 \%)$ & & & \\
\hline No & $38(92.7 \%)$ & $3(7.3 \%)$ & 1.3 & $0.3-$ & 0.4 \\
\hline
\end{tabular}

Table 2d: Association between factors related to Primary Health Care Services and bypass of primary facilities.

\begin{tabular}{|c|c|c|c|c|c|}
\hline \multirow[t]{2}{*}{ Variable } & \multicolumn{5}{|c|}{ Reasons for mothers to bypass primary health facilities } \\
\hline & Yes, n (\%) & No n (\%) & OR & $\mathrm{CL}$ & $P$ value \\
\hline \multicolumn{6}{|c|}{ Quality Health care services at primary facilities } \\
\hline Yes & $359(93.7 \%)$ & $24(6.3 \%)$ & & & \\
\hline No & $66(95.7 \%)$ & $3(4.3 \%)$ & 0.7 & $0.1-2.3$ & 0.3 \\
\hline \multicolumn{6}{|c|}{ No Privacy at PHF } \\
\hline Yes & $411(94.7 \%)$ & $23(5.3 \%)$ & & & \\
\hline No & $18(81.8 \%)$ & $4(18.4 \%)$ & 3.9 & $1.2-12.7$ & 0.03 \\
\hline \multicolumn{6}{|c|}{ No Sufficient equipment's at PHF } \\
\hline Yes & $398(94.3 \%)$ & $24(5.7 \%)$ & 1 & & \\
\hline No & 33(91.7\%) & $3(8.3 \%)$ & 1.5 & $0.4-5.3$ & 0.3 \\
\hline \multicolumn{6}{|c|}{ No Diagnostic test at PHFs } \\
\hline Yes & $339(93.9 \%)$ & $22(6.1 \%)$ & & & \\
\hline No & $90(94.7 \%)$ & $5(5.3 \%)$ & 0.9 & $0.3-2.3$ & 0.4 \\
\hline
\end{tabular}

Table 2e: Association between Clinical factors and bypass of primary facilities.

\begin{tabular}{|c|c|c|c|c|c|}
\hline \multirow[t]{2}{*}{ Variable } & \multicolumn{5}{|c|}{$\begin{array}{l}\text { Reasons for mothers to bypass primary health } \\
\text { facilities }\end{array}$} \\
\hline & Yes n (\%) & No $n(\%)$ & OR & $\mathrm{CL}$ & $P$ value \\
\hline \multicolumn{6}{|c|}{ Attended ANC at PHF } \\
\hline 4 and more times & $264(94.3 \%)$ & $27(6.4 \%)$ & & & \\
\hline Less than 4 times & $138(92.6 \%)$ & $0(0.0 \%)$ & 0.94 & $0.9-0.96$ & 0.07 \\
\hline \multicolumn{6}{|l|}{ Mode of Delivery } \\
\hline Vaginal Delivery & $438(94.4 \%)$ & $16(5.6 \%)$ & & & \\
\hline $\mathrm{C} / \mathrm{S}$ & $78(97.5 \%)$ & $11(2,5 \%)$ & 1.3 & $0.5-2.9$ & 0.3 \\
\hline \multicolumn{6}{|c|}{ Infection during pregnancy } \\
\hline Yes & 209(95.9\%) & $9(4.1 \%)$ & & & \\
\hline No & $302(94.1 \%)$ & $19(5.9 \%)$ & 1.5 & $0.6-3.3$ & 0.2 \\
\hline \multicolumn{6}{|l|}{ Name of infections } \\
\hline UTI and Malaria & $159(97 \%)$ & $5(3 \%)$ & & & \\
\hline Others & $51(92.7 \%)$ & $4(7.3 \%)$ & 2.5 & $0.6-9.5$ & 0.1 \\
\hline \multicolumn{6}{|c|}{ NCDs (hypertension and DM) } \\
\hline Yes & $28(96.6 \%)$ & $1(3.4 \%)$ & & & \\
\hline No & $488(94.8 \%)$ & $27(5.2 \%)$ & 1.6 & $0.2-11.8$ & 0.5 \\
\hline \multicolumn{6}{|c|}{ Previous birth complications } \\
\hline Yes & $42(95.5 \%)$ & $2(4.5 \%)$ & & & \\
\hline No & $469(94.7 \%)$ & $26(5.3 \%)$ & 1.2 & $0.2-5.1$ & 0.5 \\
\hline \multicolumn{6}{|l|}{ STDs } \\
\hline Yes & $10(83.3 \%)$ & $2(16.7 \%)$ & & & \\
\hline No & $501(95,1 \%)$ & $26(4,9 \%)$ & 0.3 & $0.1-1.3$ & 0.1 \\
\hline \multicolumn{6}{|c|}{ Normal HB level during pregnancy } \\
\hline Yes & $304(95.6 \%)$ & $14(4.4 \%)$ & & & \\
\hline No & $212(93.8 \%)$ & $14(6.2 \%)$ & 1.4 & $0.6-3.1$ & 0.2 \\
\hline \multicolumn{6}{|c|}{ History of Multiple pregnancies } \\
\hline No & $27(100 \%)$ & $0(0.0 \%)$ & & & \\
\hline Yes & $489(94.6 \%)$ & $28(5.4 \%)$ & 1.05 & $1.04-$ & 0.2 \\
\hline
\end{tabular}

Table 3: Association between Clinical factors and bypass of primary facilities.

\begin{tabular}{|c|c|c|c|c|c|}
\hline \multirow[t]{2}{*}{ Variable } & \multicolumn{5}{|c|}{$\begin{array}{l}\text { Reasons for mothers to bypass primary health } \\
\text { facilities }\end{array}$} \\
\hline & Yes n (\%) & No n (\%) & OR & $\mathrm{Cl}$ & $P$ value \\
\hline \multicolumn{6}{|c|}{ History of Admission during pregnancy } \\
\hline yes & $78(90.7 \%)$ & $8(9.3)$ & & & \\
\hline No & $434(95.6 \%)$ & $20(4.4 \%)$ & 0.45 & $0.1-1.1$ & 0.06 \\
\hline \multicolumn{6}{|c|}{ Weight loss during pregnancy } \\
\hline No & $80(96.4 \%)$ & $3(3.6 \%)$ & & & \\
\hline Yes & $434(94.6 \%)$ & $25(5.4 \%)$ & 1.54 & $0.4-5.2$ & 0.3 \\
\hline \multicolumn{6}{|c|}{ Number of pregnancies in the past } \\
\hline One Time & $217(95.2 \%)$ & $11(4.8 \%)$ & & & \\
\hline Two and above & & $17(5.4 \%)$ & 1.12 & $0.5-2.4$ & 0.4 \\
\hline \multicolumn{6}{|c|}{ Time between pregnancies } \\
\hline 2 years and less & $91(91.9 \%)$ & $8(8.1 \%)$ & & & \\
\hline Above 2years & & $16(5.2 \%)$ & 0.6 & $0.2-1.5$ & 0.2 \\
\hline
\end{tabular}

Citation: Hokororo JC, Eliakimu ES, Ngowi R, Mohammed MA, Malebo HM, et al. (2020) Determinants of Pregnant Mothers to Bypass Primary Health Facilities and Directly Seek Health Care in Hospitals in Dar es Salaam Region-A Cross Sectional Study. J Epidemiol Public 
multiple pregnancy, first pregnancy, rhesus factor, history of admission during pregnancy, duration between pregnancy and ANC attendance. Amongst those predictors, only one was statistically significant. That variable was 'earning more than 1USD a day' those who earned more than IUSD a day were more likely to bypass the primary facilities than those who earned less than 1USD ( $\mathrm{OR}=4.27, \mathrm{CI}=1.8-15.4, \mathrm{P}=0.01$ ).

\section{Discussion}

Dar es Salaam is the Tanzanian region with majority of health facilities 1,103 as per HFR on $01^{\text {st }}$ April 2019 than any other region in the country [7]. Most of those health facilities were primary facilities (72 health centers and 667 dispensaries). This study gives data on determinants of mothers to bypass primary healthcare facilities. The overall proportion of determinants for pregnant mothers to bypass primary healthcare facilities in Dar es Salaam region Tanzania was as high as in every 10 pregnant women; at least seven were bypassing the primary healthcare facilities to seek delivery services in hospitals.

These results were in keeping with other studies conducted in Sharg-Alneel Locality in Khartoum State Sudan by Ahmed ME, et al. [13] which found that primary healthcare facility bypass was very high at 78\% [13]. Kante AM, et al. [8] on the other side also established that more than $75.4 \%$ bypassed the primary facilities in rural Tanzania [8].

\section{Associated demographic determinants for women to bypass primary facilities and went straight to the hospitals}

Bivariate associations between potential demographic determinants of bypassing primary facilities were not significantly different from women who were given referral at their nearest facility in terms of age, socio-economic status, education, etc., except for income of the family. Clients who avoid the primary facilities and go straight to the hospitals have numerous reasons to do so. In this study different reasons have been explored to find out which determinants real explained the causes of bypass of primary facilities in Dar es Salaam.

The study has established some demographic factors of women that bypassed the primary facilities. Number one was those who are above 18 years (whom were the majority [99\%]) and out of them (95\%) bypassed the primary facilities. This explains that those who are free to make decision do prefer going directly to the higher levels of healthcare provision. These study findings were in keeping with the study by Visser CA, et al. [25] at Letaba Hospital South Africa in which they found that women between the ages of 20 and 40 years were 173 (59.05\%) (Mean age: 29.39 years; 95\% CI: 27.63-31.15,) though in our study it was not statically significant [25].

The second demographic factor that was explored was marital status of the women. Our study demonstrates that those who were married (94\%) did not go to the primary facilities and instead they went directly to the secondary or tertiary level. Probably the husbands have the influence to their wives to bypass the primary facilities. The main reason of this overestimate might be explained again with the difference in geographical and residence of the population. The latter was carried out in rural north east of Tanzania.

The third demographic reason was level of education for both mother and the spouse. Our study established that the level of education of women, and/or spouse were more likely to influence bypass of primary facilities. In urban area like Dar es Salaam, it is likely that majority are having education at least that of secondary level and hence tends to choose healthcare services at secondary and above levels. This is also echoed by the study done by Visser CA, et al. [25] at Letaba Hospital South Africa which found that 186 (63.48\%) women/ spouse with secondary or tertiary education and more bypassed the primary facility [25]. Other demographic factors that were explored are occupation of the spouse and daily income of the family. It was found that (92\%) of those who had income of more than 1USD a day were bypassing the primary facilities. This is the only variable which was statistically significant $(\mathrm{p}=0.002)$. This can be explained by the fact that those who are financially capable were bypassing the primary facilities because they can afford cost of healthcare at any level.

\section{Primary healthcare services associated determinants for women to bypass primary facilities and go straight to the hospitals}

Generally, factors related to healthcare services determine the quality of the healthcare services. Majority of those who were interviewed admitted that those were not the reasons for them to bypass. The factors were: treatment with courtesy by clinicians/nurses, cleanliness of the facility, enough time for provider-patient interaction, access to information, availability of medicines, easy access to secondary/ tertiary facilities, quality of healthcare services in general, availability of equipment and availability of diagnostic tests. These factors were not statistically significant except for those who said there was no privacy in primary facilities. The privacy in many of primary facilities is not at the expected standard level. This is because of inadequate buildings to cater for all services provided at the facility. Some of the services are provided in one room. There is lack of screens, and the rooms are not sound proof. Other studies have shown unavailability of these standard measures lead clients to bypass those facilities. We need all measures of quality to be attained in all levels so as to minimize the tendency of our clients to bypass the primary level.

\section{Associated clinical services associated determinants for women to bypass primary facilities and go straight to the hospitals}

Clinical Services are key in safe healthcare services and if healthcare facilities are not providing the quality clinical services people might abandon the use of those facilities. Those reasons led this study to explore the parameters that pertain to clinical services. The parameters which were explored are: attendance to the antenatal care; mode of delivery; history of infection, name of infection, history of NCDs, previous pregnancy complication; STDs; History of admission during pregnancy; weight loss during pregnancy; number of pregnancies in the past; duration between pregnancies. Even though the majority have experienced one or more of those parameters, none of them were statistically significant. However, in other studies these factors were found to be significant. For example, the findings from the study by Kante AM, et al. [8] conducted at rural Tanzania in 2016, he found out that mothers who reported a complication during their current pregnancy had higher odds of bypassing their nearest facility for childbirth than those who did not.

\section{Limitations of the Study}

Selection and social desirability response bias might have affected the accuracy of the data collected as the participants were sampled from hospitals only. This might have led to overestimation of the proportion of mothers who had bypassed primary facilities and go straight to the secondary and tertiary facilities as majority of mothers are serviced in lower levels of healthcare delivery and many delivers at home. Improved data collection with use of knowledgeable trained research assistants and follow up of research assistants through regular meetings and supervision may have helped on the correctness and reliability of collected data. Hence, despite of these limitations, our findings can be generalized to the target population. 


\section{Conclusions}

This study has found postnatal women in Dar es Salaam region are at high chance of going straight to level one and level 2 hospitals without passing at primary facilities. Seven in every ten postnatal women interviewed in this study had bypassed the primary facilities. Further, pregnant women of Dar es Salaam Region from families that earn more than IUSD a day are four times more likely to get to the upper facilities without referral from primary facilities. Hence, there is a need to strengthen the primary health care in the country so as those with no complication should get care in that level. That will reduce congestion at level 1 and level 2 hospitals and hence, enabling the hospitals to provide quality services to those referred from primary level.

The findings from this study may be useful to policy makers in identifying strategies that will reinforce the existing guidelines; complement the existing body of knowledge; and may be used to generate the mechanism of implementing the policy that can build capacity of primary health facilities in Dar es Salaam region. The information also can be used as the basis for further studies.

\section{Declarations}

\section{Ethics approval and consent to participate Ethical consideration}

To ensure ethically sound research and "safeguard the dignity, rights, safety and well-being of research participants", an Institutional Review Board (IRB) approval by Medical Research Coordinate Committee of the National Institute for Medical Research (NIMR) was obtained prior to initiation of the study. The entire research team including PI, Co PIs, researchers and study coordinators completed training for human subject research for research ethics, which was provided as part of survey, or training before study begins.

\section{Informed consent form and written information sheet}

Informed consent form and written information sheet were used to make sure that the participants are fully aware of the nature of the study. An informed consent form along with written information was provided during the recruitment of study participants. In case the potential participants do not agree to sign the informed consent form, they were excluded from the study. Participants had opportunity to withdraw from the study at any point in time. For the post-natal women below 15 years old, the team requested for special permission to treat them as emancipated minors so as they could consent by themselves. The written information sheet includes the purpose of the study, procedure, any risks or harms, benefits and details about confidentiality written in simple, understandable language.

\section{Consent for publication-optional}

In Tanzania, the clearance from the Review Board (IRB) approval by Medical Research Coordinate Committee of the National Institute for Medical Research (NIMR) is enough to disseminate to various stakeholders including peer review journals.

\section{Availability of data and material}

Data and all materials used during the study are submitted with this manuscript

\section{Competing Interests}

There were no competing interests amongst the authors.

\section{Authors' contributions}

The PI had initiated, designed, planned, managed and supervised the overall study.

The Co-PIs had collaborated with the PI to coordinate and supervise the overall study activities, including reviewing study design, data collection tool, and analyzed data results.

Researchers were responsible for assisting design, planning, managing and analyzing the overall study.

Research coordinators were responsible for coordinating overall research work, including recruiting and training surveyors, preparing survey sheets, and communicating with stakeholders for smooth implementation of the research.

A professional data consultant with previous experience in survey design reviewed the overall study design and sampling technique.

Surveyors or research assistants collected the data from the health facilities.

\section{Acknowledgment}

First and foremost, we thank the almighty God for giving us strength and courage throughout the period of development of this research.

Secondly, we extend our gratitude to the Ministry of Health, Community Development, Gender, Elderly and Children (MoHCDGEC) through the Division of Health Quality Assurance for their participation and follow-up of this study.

We would like also to thank Medipeace Tanzania which is a global health Non-Governmental Organization (NGO) from South Korea and Embassy of the United States of America for agreeing Oliver Roberts to support and assist the study preparation, data collection, analysis and report writing.

Many thanks go to all Co-Principal Investigators of this study for their priceless input in this study.

\section{References}

1. Maternal Mortality Fact sheet. World Health Organization, Geneva, Switzerland.

2. United Nations (2015) Transforming our world: the 2030 Agenda for Sustainable Development. Seventieth session Agenda items 15 and 116. A/RES/70/1. Resolution adopted by the General Assembly on 25 September 2015.

3. Millennium Development Goals (2017) United Nations, New York, USA.

4. United Nations Development Programme (2017) SustainableDevelopment-Goals.

5. The United Republic of Tanzania, Ministry of Health and Social Welfare (2007) Primary Health Services Development ProgrammeMMAM 2007-2017.

6. The United Republic of Tanzania, Ministry of Health and Social Welfare and Prime Minister's Office Regional Administration and Local Government (2013) Summary and Analysis of the Comprehensive Council Health Plans 2013/2014.

7. Ministry of Health, Community Development, Gender, Elderly and Children (2019) The United Republic of Tanzania, 2019. Health Facility Registry.

8. Kanté AM, Exavery A, Phillips JF, Jackson EF (2016) Why women bypass front-line health facility services in pursuit of obstetric care provided elsewhere: a case study in three rural districts of Tanzania. Trop Med Int Health 21: 504-514. 
9. Audo MO, Ferguson A, Njoroge PK (2005) Quality of health care and its effects in the utilisation of maternal and child health services in Kenya. East Afr Med J 82: 547-553.

10. Escamilla V, Calhoun L, Winston J, Speizer IS (2018) The Role of Distance and Quality on Facility Selection for Maternal and Child Health Services in Urban Kenya. J Urban Health 95: 1-12.

11. Cohen J, Golub G, Kruk ME, McConnell M (2016) Do active patients seek higher quality prenatal care?: A panel data analysis from Nairobi, Kenya. Prev Med 92: 74-81.

12. Yaffee AQ, Whiteside LK, Oteng RA, Carter PM, Donkor P, et al. (2012) Bypassing proximal health care facilities for acute care: a survey of patients in a Ghanaian Accident and Emergency Centre. Trop Med Int Health 17: 775-781.

13. Ahmed ME, Mahdi TE, Ahmed NJO (2017) Bypassing Primary Health Care Facilities for Common Childhood Illnesses in Sharg-Alneel Locality in Khartoum State, Sudan 2015. Sci J Public Health 5: 77-87.

14. Sharma J, Leslie HH, Regan M, Nambiar D, Kruk ME (2018) Can India's primary care facilities deliver? A cross-sectional assessment of the Indian public health system's capacity for basic delivery and newborn services. BMJ Open 8: e020532.

15. Salazar M, Vora K, Costa AD (2016) Bypassing health facilities for childbirth: a multilevel study in three districts of Gujarat, India. Glob Health Action 9: 32178

16. Sabde Y, Chaturvedi S, Randive B, Sidney K, Salazar M, et al. (2018) Bypassing health facilities for childbirth in the context of the JSY cash transfer program to promote institutional birth: A cross-sectional study from Madhya Pradesh, India. PLoS One 13: e0189364.

17. Yao J, Agadjanian V (2018) Bypassing health facilities in rura Mozambique: spatial, institutional, and individual determinants. BMC Health Serv Res 18: 1006.

18. Shah R (2016) Bypassing birthing centres for child birth: a community-based study in rural Chitwan Nepal. BMC Health Serv Res16: 597.

19. Fleming LC, Ansumana R, Bockarie A, Alejandre J, Bangura U, et al. (2016) Inpatient healthcare provider bypassing by women and their children in urban Bo, Sierra Leone. Pan Afr Med J 23: 146.
20. Perera SK, Weerasinghe MC (2015) Bypassing Primary care in Sri Lanka: A Comparative Study on Reasons and Satisfaction. Vietnam J Public Health 3: 69-76.

21. Parkhurst JO, Ssengooba F (2009) Assessing access barriers to maternal health care: measuring bypassing to identify health centre needs in rural Uganda. Health Policy Plan 24: 377-384.

22. Legal and Human Rights Centre (2016) Tanzania Human Rights Report 2015. Tanzania Mainland, LHRC, Dar es Salaam, Tanzania.

23. Kruk ME, Mbaruku G, McCord CW, Moran M, Rockers PC, et al. (2009) Bypassing primary care facilities for childbirth: a populationbased study in rural Tanzania. Health Policy Plan 24: 279-288.

24. Kruk ME, Hermosilla S, Larson E, Mbaruku GM (2014) Bypassing primary care clinics for childbirth: a cross-sectional study in the Pwani region, United Republic of Tanzania. Bull World Health Organ 92: 246-253.

25. Visser CA, Marincowitz GJO, Govender I , Ogunbanjo GAO (2015) Reasons for and perceptions of patients with minor ailments bypassing local primary health care facilities. South African Family Practice 57: 333-336.

26. Simba DO, Mbembati NA, Museru LM, Lema LE (2008) Referra pattern of patients received at the national referral hospital: challenges in low income countries. East Afr J Public Health 5: 6-9.

27. Nkuwi EJ, Kabanangi F, Joachim A, Rugarabamu S, Majigo M (2018) Methicillin-resistant Staphylococcus aureus contamination and distribution in patient's care environment at Muhimbili National Hospital, Dar es Salaam-Tanzania. BMC Res Notes 11: 484.

28. Manyahi J, Matee MI, Majigo M, Moyo S, Mshana SE, et al. (2014) Predominance of multi-drug resistant bacterial pathogens causing surgical site infections in Muhimbili National Hospital, Tanzania. BMC Res Notes 7: 500

29. Founou RC, Founou LL, Essack SY (2017) Clinical and economic impact of antibiotic resistance in developing countries: A systematic review and meta-analysis. PLoS One 12: e0189621.

30. Shoo RS, Mboera LEG, Ndeki S, Munishi G (2017) Stagnating maternal mortality in Tanzania: what went wrong and what can be done. Tanzan J Health Res 19: 1-12. 